\title{
Chemical characterization of volatile oils of different parts of Satureja
}

\section{Bachtarica Bunge}

\author{
Mohammad Hadi Meshkatalsadat ${ }^{*}$, Khadijeh Rabiei, Yaghub Shabaninejad \\ Department of Chemistry, Faculty of Basic Science, Qom University of Technology, Qom, 37195, Iran. \\ E-mail addresses: mhmeshkatalsadat@yahoo.com, meshkatalsadat.m@qut.ac.ir.
}

Fax No:+98-25-36661604

\begin{abstract}
In this study, essential oils from different organs of Satureja bachtiarica Bunge were obtained by hydro-distillation. Quality and quantity of chemical composition of essential oils were determined by capillary gas chromatography and using gaschromatography and mass spectrometric detection. The numbers of compounds were identified in the essential oils of leaves; stem and aerial parts were 45, 39 and 35, respectively. Also, carvacrol was the main component found in essential oils from leaves $(39.3 \%)$, stem $(39.4 \%)$ and aerial parts $(67.88 \%)$ of $S$. bachtiarica in flowering stage. In addition, results showed that there were some different in compositions of the essential oils of different parts of $S$. bachtiarica and there are some minor components in each oil that are not present in the others parts. In addition chemical analysis of essential oils obtained from leaves and stem of $S$. bachtiarica were rich in oxygenated monoterepens $(55.64 \%$ and $67.53 \%)$ while oxygenated monoterepen $(77.22 \%)$ were the main class of compounds in the essential oils from aerial parts of $S$. bachtiarica. Results of this study showed that the essential oils from different organs of $S$. bachtiarica have a potential to be used as a new carvacrol source in drug and food industries.
\end{abstract}

\section{Keywords}

Satureja bachtiarica; Lamiacea; essential oil; carvacrol; 4-terpineol.

\section{Council for Innovative Research}

Peer Review Research Publishing System

\section{Journal: Journal of Advances in Chemistry}

Vol. 5, No. 2

editor@cirworld.com

www.cirworld.com, member.cirworld.com 


\section{INTRODUCTION}

The genus Satureja belongs to the family Lamiaceae, subfamily Nepetoideae and the tribe Saturejeae, and comprises more than 200 species of herbs and shrubs, mainly distributed in the Mediterranean region. The flora of Iran has 14 Satureja species; nine species are endemic, which commonly found in Rocky Mountains [1-4]. Satureja bachtiarica Bunge., one of these species, is an aromatic herb with little flowers $(1.5 \mathrm{~mm})$, linear to lineaoblanceolate leaves that complexes on stem, the under and surface of their leaves are hire-covered and it grows wild on rocky or eroded slopes, gravelly places and coastal dunes, fallow fields and roadsides, in west, center and southwest in Iran [5].

One of the diagnostic characteristics of the subfamily Nepetoideae is that its representatives contain more than $0.5 \%$ of essential oil, and Satureja hortensis L. and Satureja montana L. are two notable Satureja species in the world that have several uses in medicinal and food industries [6,7]. The leaves, flowers and stems of Satureja species are used as herbal tea, in production of traditional medicine to treat various ailments such as cramps, muscle pains, nausea, indigestion, diarrhea and infectious diseases [8-11]. In addition, it is reported that a 3 infusion of the aerial parts of $S$. brevicalix is used as a digestive, a gastralgie, an antispasmodic and to help in parturition [8]. Satureja kitaibelii is used to treat bronchitis in adults and children, while also used to treat skin, respiratory, digestive and urinary inflammation. An infusion of $S$. brownei is used as a remedy for respiratory diseases and cough [12]. In the recent years, several studies to investigation the biological properties of active substance extracted from Satureja species, such as extracts, essential oils and their constituents, planned and as a result, antiviral, antinociceptive, anti-inflammatory, antibacterial, antifungal, antispasmodic, antidiarrhea and vasodilatory activity of these substances documented $[3,6,13,14]$.

Due to these properties and usages of Satureja species or their oils, many phytochemical studies so far investigated the chemical composition of essential oil from Satureja species from different sources and chemotypes as well as its variation in different seasons and during the plant life cycle [4, 15-17]. In addition, chemical characterization of essential oils from five endemic Satureja species of Iran, S. bachtiarica [18], Satureja khuzistanica Jamzad [6] Satureja intermedia C.A. Mey. [19] Satureja sahandica Bornm. [16] and Satureja rechingeri Jamzad [4] were reported previously.

The major compounds found in S. bachtiarica oil were thymol $(44.5 \%)$ and $\mathrm{y}$ - terpinene $(23.9 \%)$. The oil of $S$. khuzistanica was particularly rich in $\rho$-cymene (39.6\%) and carvacrol (29.6\%). Thymol (19.6-41.7\%), $\rho$-cymene $(32.5-54.9 \%)$ and $\gamma$ terpinene $4(1.0-12.8 \%)$ were the main components of $S$. sahandica oil, while that the major compound of $S$. rechingeri was carvacrol (84.0-89.3\%). At the same time, S. intermedia oil contained thymol (32.3\%), $\gamma$-terpinene $(29.3 \%)$ and $\rho$ cymene $(14.7 \%)$.

Essential oils are aromatic oily liquids obtained from different plant materials. They are highly complex mixtures of mono (C10) and sesquiterpenes (C15), including biogenetically related phenols [20, 21]. Biological activities of essential oils depends on the qualitative and quantitative of their components, which it is affected by the plant genotype, plant chemotype, organ of plant, geographical origin, season, environmental, agronomic conditions, extraction method and storage condition of plant and essential oils [22, 23].

Until now, we have found only one published report on phytochemical composition of $S$. bachtiarica, therefore, in the present study for the first time; essential oils of stem, leaves and aerial parts of $S$. bachtiarica were obtained separately and analyzed by GC and GC-MS.

\section{RESULTS AND DISCUSSION}

The results obtained by GC and GC-MS analyses of the essential oils used in this study are presented in Table 1. The oils were yellow in color and had distinct sharp odor. The yield of essential oils distilled from leaves, stem and aerial parts of $S$. bachtiarica were $1.54 \% \mathrm{w} / \mathrm{w}, 0.98 \%$ and $1.32 \%$, respectively. Also, total ion chromatograms of volatile compounds from leaves, stem and aerial parts of tested plant were shown (Fig. 1-3).

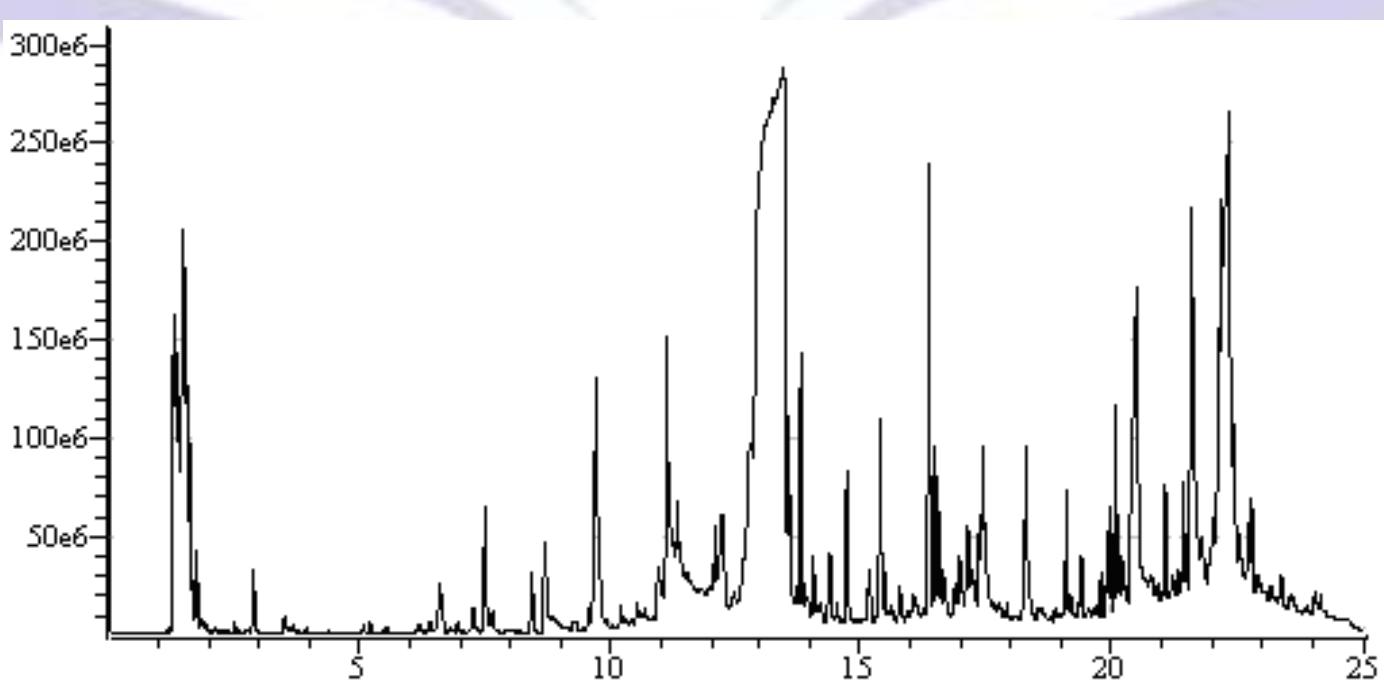

Fig. 1. GC-MS total ion chromatograms of volatile compounds from leaves of S. bachtiarica Bunge. 


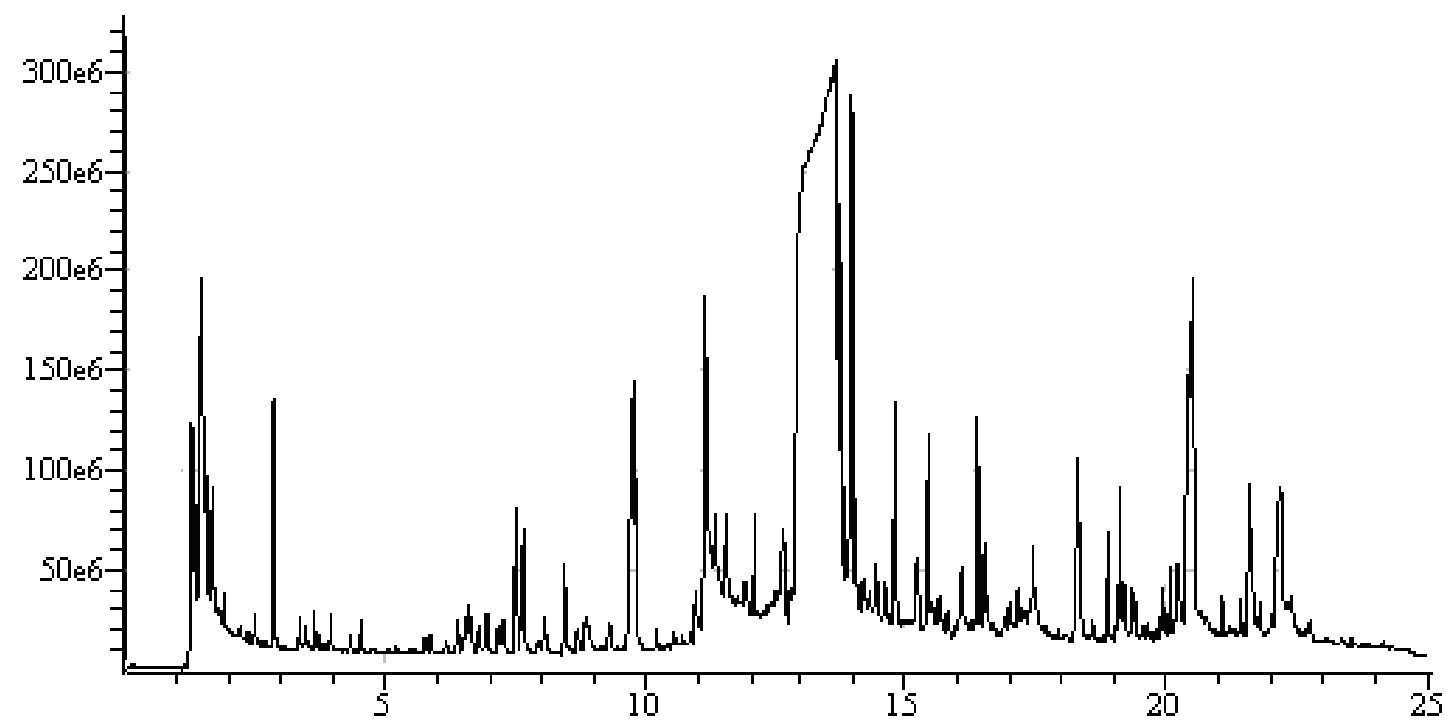

Fig. 2. GC-MS total ion chromatograms of volatile compounds from stems of $S$. bachtiarica Bunge.



Fig. 3. GC-MS total ion chromatograms of volatile compounds from aerial parts of $S$. bachtiarica Bunge.

In the leaf essential oil, forty-five constituents, representing $88.11 \%$ of the total components in the oil characterized. The major compounds were carvacrol (39.3\%), palmitic acid (5.13\%), a-terpineol (3.21\%), 4-terpineol (2.62\%) and linalool $(2.08 \%)$. The stem essential oil characterized by thirty-nine constituents, representing $93.50 \%$ of the total components in the oil and its major compounds were carvacrol (39.40\%), palmitic acid (9.49\%), 4-terpineol (5.40\%), linalool (5.10\%) and a- terpineol (2.79\%), respectively. In addition chemical analyses of essential oils obtained from leaves and stem of $S$. bachtiarica contained oxygenated monoterepens (55.64\% and $67.53 \%)$, oxygenated sesquiterepens (15.14\% and $20.12 \%)$, sesquiterepens (1.36\% and $2.02 \%)$ and monoterepens $(0.75 \%$ and $1.94 \%)$, respectively (Table 1$)$. In addition, Thirty five constituents, representing $89.01 \%$ of the total components in the oil of aerial parts of S. bachtiarica, identified and its major compounds were carvacrol $(67.88 \%)$, 4-terpineol $(2.93 \%)$, linalool $(2.56 \%)$ and $\rho$-cymene $(1.85 \%)$. Also, oxygenated monoterepen $(77.22 \%)$, monoterepen $(4.48 \%)$, oxygenated sesquiterepen $(3.4 \%)$ and sesquiterepen $(2.74 \%)$ were the main class of compounds in the aerial parts of $S$. bachtiarica (Table 1 ). 
Table 1. The chemical composition of essential oils obtained from leaves, stem and aerial parts of Satureja Bachtiarica Bunge

\begin{tabular}{|c|c|c|c|c|c|c|}
\hline \multirow[t]{2}{*}{ No } & \multirow[t]{2}{*}{ Compounds } & \multirow[t]{2}{*}{$\mathrm{RI}^{*}$} & \multicolumn{4}{|c|}{ Essential oils } \\
\hline & & & Leaves (\%) & Stem (\%) & $\begin{array}{l}\text { Aerial } \\
(\%)\end{array}$ & parts \\
\hline 1 & $\alpha$-Thujene & 930 & 0.03 & 0.03 & 0.15 & \\
\hline 2 & $\alpha$-Pinene & 939 & 0.03 & 0.05 & 0.20 & \\
\hline 3 & $\beta$-Myrcene & 991 & 0.05 & ---- & 0.58 & \\
\hline 4 & $\alpha$-Phellandrene & 1003 & 0.03 & ---- & 0.08 & \\
\hline 5 & $\beta$-Phellandrene & 1030 & ---- & 0.05 & ---- & \\
\hline 6 & $\alpha$-Terpinene & 1017 & 0.05 & 0.18 & 0.47 & \\
\hline 7 & $p$-Cymene & 1025 & 0.65 & 1.66 & 1.85 & \\
\hline 8 & $y$-Terpinene & 1060 & 0.23 & 1.05 & 1.18 & \\
\hline 9 & cis-Sabinene Hydrate & 1070 & 0.73 & ---- & 0.49 & \\
\hline 10 & trans-Linalool oxide & 1073 & 0.06 & ---- & ---- & \\
\hline 11 & trans-Sabinene hydrate & 1098 & 0.06 & & --- & \\
\hline 12 & Terpinolene & 1089 & ---- & ---- & 0.25 & \\
\hline 13 & Linalool & 1097 & 2.08 & 5.10 & 2.56 & \\
\hline 14 & 1,8-Cineol & 1031 & 0.05 & 1.71 & 0.10 & \\
\hline 15 & Camphor & 1146 & --- & 0.03 & ---- & \\
\hline 16 & cis-Limonene oxide & 1137 & --- & 0.03 & ---- & \\
\hline 17 & P-Menth-2-en-1-ol & 1131 & 0.09 & ---- & ---- & \\
\hline 18 & trans-Pinene hydrate & 1123 & 0.06 & 0.16 & ---- & \\
\hline 19 & trans-Pinocarveol & 1139 & ---- & ---- & 0.06 & \\
\hline 20 & Cuminal & 1242 & --- & 0.80 & ---- & \\
\hline 21 & Borneol & 1169 & 0.74 & 0.83 & 0.44 & \\
\hline 22 & 4-Terpineol & 1177 & 2.62 & 5.40 & 2.93 & \\
\hline 23 & p-Cymene-8-ol & 1183 & 0.37 & 1.18 & ---- & \\
\hline 24 & $\alpha$-Terpineol & 1189 & 3.23 & 2.79 & 1.25 & \\
\hline 25 & Cis-Dihydro carvone & 1193 & ---- & --- & 0.28 & \\
\hline 26 & trans-Dihydro carvone & 1201 & ---- & 1.20 & ---- & \\
\hline 27 & $\begin{array}{l}\text { cis-p-Menth-1 (7),8-diene- } \\
\text { 2-ol }\end{array}$ & 1231 & 0.53 & ---- & ---- & \\
\hline 28 & Thymol methyl ether & 1235 & 1.50 & 1.32 & 0.32 & \\
\hline 29 & Decanal & 1197 & 1.21 & 2.63 & ---- & \\
\hline 30 & Carvacrol & 1299 & 39.30 & 39.40 & 67.88 & \\
\hline 31 & Eugenol & 1359 & 0.91 & 2.38 & 0.66 & \\
\hline 32 & Thymyl acetate & 1352 & 0.36 & ---- & ---- & \\
\hline 33 & trans- $\beta$-Damascenone & 1358 & 0.13 & 0.09 & ---- & \\
\hline 34 & trans-Caryophyllen & 1419 & 0.43 & 0.19 & 0.42 & \\
\hline
\end{tabular}




\begin{tabular}{|c|c|c|c|c|c|}
\hline 35 & Geranyl acetone & 1455 & 0.66 & ---- & 0.79 \\
\hline 36 & $\beta$-lonene & 1489 & 0.39 & 0.59 & 0.26 \\
\hline 37 & $\beta$-Bisabolene & 1506 & 0.88 & 1.31 & 1.19 \\
\hline 38 & Cis-Nerolidol & 1533 & ---- & 1.20 & ---- \\
\hline 39 & $\alpha$-Humulene & 1455 & 0.09 & ---- & 0.08 \\
\hline 40 & trans-Nerolidol & 1563 & 0.05 & ---- & T0.03 \\
\hline 41 & Cis- $\alpha$-Bisabolene & 1507 & ---- & 0.12 & ---- \\
\hline 42 & Dodecanoic acid(lauric) & 1567 & 0.57 & 1.46 & ---- \\
\hline 43 & Caryophyllene oxide & 1583 & 1.58 & 2.09 & 1.37 \\
\hline 44 & $\beta$-Eudesmol & 1651 & 0.90 & 0.92 & 0.36 \\
\hline 45 & Spathulenol & 1578 & 0.63 & 0.10 & ---- \\
\hline 46 & 10-epi-y-Eudesmol & 1624 & 0.45 & 0.08 & 0.03 \\
\hline 47 & Elemol & 1550 & 0.03 & ---- & 0.06 \\
\hline 48 & Guaiol & 1601 & 0.59 & ---- & --- \\
\hline 49 & Agarospirol & 1648 & 0.83 & 0.94 & 0.09 \\
\hline 50 & $\alpha$-Bisabolol & 1686 & 1.93 & 1.05 & 0.51 \\
\hline 51 & Farnesol & 1701 & 0.03 & ---- & ---- \\
\hline 52 & $\begin{array}{ll}\text { Tetra } & \text { decanoic } \\
\text { acid(Myristic) } & \end{array}$ & 1750 & 1.74 & 3.05 & 0.09 \\
\hline 53 & Farnesyl acetone & 1865 & 0.52 & 0.88 & 0.05 \\
\hline 54 & Palmitic acid & 1938 & 5.13 & 9.49 & 0.87 \\
\hline \multicolumn{2}{|c|}{ Total } & & $88.11 \%$ & $93.5 \%$ & $88.11 \%$ \\
\hline \multicolumn{2}{|c|}{ Yield \% (w/w) } & & $1.54 \%$ & $0.98 \%$ & $1.23 \%$ \\
\hline \multicolumn{2}{|c|}{ Monoterepen } & & 0.75 & 1.94 & 4.48 \\
\hline \multicolumn{2}{|c|}{ Oxygenated monoterepen } & & 55.40 & 67.53 & 77.22 \\
\hline \multicolumn{2}{|c|}{ Sesquiterepen } & & 1.36 & 2.02 & 2.74 \\
\hline \multicolumn{2}{|c|}{ Oxygenated Sesquiterepen } & & 15.14 & 20.12 & 3.40 \\
\hline
\end{tabular}

Results showed that there were some different in compositions of the essential oils of different parts of $S$. bachtiarica and there are some minor components in each oil that are not present in the others parts.

The essential oils from leaves, stem and aerial parts of Iranian S. bachtiarica have been planned for the first time and the chemical composition these organs compared with oil contents and compositions of the other Satureja species. Assessment prevalent compounds available in different parts of $S$. bachtiarica showed that carvacrol is the main component in leaves, stem and aerial parts of plant $(39.3 \%, 39.4 \%$ and $67.88 \%)$, respectively and the percentage of carvacrol in aerial parts were higher than plant leaves and stems. These results were in agreement with report of [18] that stated thymol (44.5\%) was the main component available in essential oil extracted from S. bachtiarica. On the other hand, comparison of the major components of other Satureja species with our study showed that our results were agree with results of [19] and [4] that reported carvacrol is the prevalent constituent in their studied $S$. mutica $(30.9 \%)$ and $S$. rechingeri (89.3\%). But in this respect, there were differences with other species such as S. spicigera [27]. S. sahendica [16], S. intermedia [19] that thymol were their major components.

The percentages of essential oils were acceptable on comparison with other Satureja species. The highest oil yield was obtained from S. mutica $(2.31 \%)$ and the oil yields of both of the other species were about $1.5 \%$. Due to the high amounts of carvacrol, and other terpenoids in the oils of $S$. bachtiarica and similarity of the oil composition to $S$. hortensis and $S$. montana, it can be concluded that the herbs and essential oils of $S$. bachtiarica can be used as flavoring agents in food and also in the medicinal and perfume industries. The low amounts of phenols, of $\rho$-cymene and linalool in the oil of $S$. 
bachtiarica, suggest that this plant could have specific usage in the medical industry. This should be tested in further research.

\section{EXPERIENTAL SECTION}

\section{Planet Material}

The fresh leaves stem and aerial spices of Satureja bachtiarica Bunge were collected during the flowering stage of plant from Highland of Zagros Mountain (1600-2200 m above sea level) in llam province in the West of Iran, in April 2008. All samples were air dried and stored at room temperature in darkness until distillation.

\section{Extraction of the Essential Oil}

The essential oil of all air-dried samples $(100 \mathrm{~g})$ was isolated by hydro-distillation for $2-4 \mathrm{~h}$, using a Clevenger-type apparatus according to the method recommended in British Pharmacopoeia [24]. The distillated oils were dried over anhydrous sodium sulfate and stored in tightly closed dark vials at $4{ }^{\circ} \mathrm{C}$ until use and further analysis.

\section{GC and GC/MS Analysis}

GC analyses were carried out on a Shimutzu 17A gas chromatograph equipped with a FID (Flame lonization Detector) and a BP-10 (non-polar) capillary column $(30 \mathrm{~m} \times 0.32 \mathrm{~mm} ; 0.25 \mu \mathrm{m}$ film thickness). The oven temperature was held at 60 ${ }^{\circ} \mathrm{C}$ for $3 \mathrm{~min}$ then programmed at $5^{\circ} \mathrm{C} / \mathrm{min}$ to $260{ }^{\circ} \mathrm{C}$. Other operating conditions were as follows: Carrier gas He, at a flow rate of $5 \mathrm{ml} / \mathrm{min}$; injector temperature $230{ }^{\circ} \mathrm{C}$; detector temperature $245^{\circ} \mathrm{C}$; split 40 , column flow ratio, $1: 8 \mathrm{ml} / \mathrm{min}$. GC/MS analyses were performed on a Shimutsu 17A GC coupled with Shimutsu QP5050A Mass system. The operating conditions were the same conditions as described above but the carrier gas was He. Mass spectra were taken at $70 \mathrm{eV}$. Mass range was from m/z 50-500 amu. Quantitative data was obtained from the electronic integration of the FID peak areas. The components of the oil were identified with the comparison of their mass spectra and retention indices with those published in the literature [25, 26] and presented in the MS computer library (WILEY229.L and NIST 1998).

\section{AKNOWLEDGMENT}

We are grateful to The University of Technology of Qom Research Council for the partial support of this work.

\section{REFERENCES}

[1] P. D. Cantino, P. D., Harley, R. M., Wagstaff, S. J. Advances in Labiatae Science. Royal Botanic Gardens, Kew, (1992) 511.

[2] Pedersen, J. A. Biochem. Syst. Ecol. 28 (2000) 229

[3] Sonboli, A., Fakhari, A., Kanani, M. R., Yousefzadi, M. Antimicrobial Zeitschrift fur Naturforschung, 59 (2004) 777.

[4] Sefidkon, F., Abbasi, K., Jamzad, J., Ahmadi, S. Food. Chem. 100 (2007) 1054.

[5] Sefidkon, F., Sadeghzadeh, L., Teimouri, M., Asgari, F., Ahmadi, S. Iranian J. Med. Arom. Plants, 23 (2007) 174.

[6] Sefidkon, F., Ahmadi, S. J. Essent. Oil Res., 12 (2000) 427.

[7] Kurcuoglu, M., Tumen, G. Baser, K. H. C. Chem. Nat. Comd., 37 (2001) 329.

[8] Rechinger, K. H., Satureja. Flora Desiranischen Hoclandes and der Umrahmenden Gebirge,. Akademische Druku Verlags Antalt Graz, Austria, (1982).

[9] Hajhashemi, V., Sadraei, H., Ghanadi, A. R., Mohseni, M. J. Ethnopharmacol, 71 (2000) 187.

[10] Rojas, L. B., Usubillaga, A., Flavour Frag. J., 151 (2000) 21.

[11] Baydar, H., Sagdic, O., Ozkan, G., Karadogan, T. Food Control, 15 (2004) 169.

[12] Cazin, C., Jonard, R., Allain, P., Pellecure, J. L'evolution de la composition des huiles essentielles chez divers chemotypes de Sarriette des montangnes Satureja montana L. obtenus par l'isolement in vitro des apex. C.R. Acad. Sc. Paris. (1985).

[13] Tumen, G., Baser, K. H. C., Demi, C. I. B., Ermin, N. Flavour Frag. J., 131 (1998) 65.

[14] Viturro, C. I. A., Moina, A., Guy, I., Charles, B., Guinaudeau, H., Fournet, A. Argentina. Flavour Frag. J., 156 (2000) 377.

[15] Slavkovska, V., Jancic, R., Bojovic, S., Milosavljevic, S., Djokovic, D. Phytochem., 57 (2001) 71.

[16] Sefidkon, F., Jamzad, Z., Mirza, M. Food Chem., 88 (2004) 325.

[17] Ćavar, S., Maksimović, M., Šolić, M. E., Jerković-Mujkić, A., Bešta, R. Food Chem., 111, (2008) 648.

[18] Sefidkon, F., Jamzad, Z. J. Essent. Oil Res., 12 (2000) 545. 
[19] Sefidkon, F., Jamzad, Z. Food Chem., 91 (2005) 1.

[20] Burt, S., Int. J. Food Microbiol., 94 (2004) 223.

[21] Isman, M. B., Machial, C. M., Naturally accruing bioactive compounds, 29 (2006).

[22] Marotti, M. Dellacecca, V.; Piccaglia, R.; Giovanelli, E. Netherlands, (1992) 19.

[23] Suhr, K.I. Nielsen, P.V. J. Appl. Microbiol., 94 (2003) 665.

[24] Maissoneuve, S. A. Ruffine, S. European Pharmacopoeia, (1983).

[25] Davies, N.W. J. Chromatogr., 503 (1990) 1.

[26] Adams, R.P. Identification of Essential Oil Components by Gas Chromato-Graphy/mass Spectroscopy. Allured Publishing Corp, Carol Stream, USA (1995).

[27] Sefidkon, F. Jamzad, Z.. Flavour Frag. J., 19 (2004)571. 